\title{
Stainless Steele and heavy metal health
}

\author{
John Milne - Chair, General Dental Practice Committee \\ Peter Bateman - Chair, Salaried Dentists Committee
}

Professor Steele and his team have been zooming around the country for several months, talking with dentists, patient groups, primary care trusts, the Department for Health and anyone interested in enabling the NHS dental service to develop in a way that even begins to address the needs of the population of England. The energy and commitment of the review team has produced a thoughtful and provocative, but realistic, report that can be welcomed by the profession and government alike.

Professor Steele acknowledges outstanding levels of care are being offered to patients within the NHS. This is a tribute to the skill, ethics and professionalism of dentists. It has been achieved, some would argue, despite rather than because of the current NHS contractual system.

The report recommends that "health should now be the desired outcome for NHS dentistry' and changing the current ways of working to enable this will be a challenge for the profession over the coming months and years. Professor Steele wisely suggests that, in the long term, improvements in oral health will demonstrate prudent spending of scarce NHS resources rather than merely producing more dentistry. A shift towards a properlyresourced pathway of care with prevention at the core is one that will surely be endorsed by the profession, particularly as it is accompanied in the report by a clear message that patients who desire only sporadic care must also be catered for.

Those born in the post-war period note with a sense of amusement the report's description of a 'heavy metal generation,' whose mouths have often been heavily restored and will present a considerable challenge to maintain in the next few years, and also a further challenge in the longer-term as many of these aged rockers begin to enter care homes in years to come. Dentists in salaried services understand this looming challenge all too well.

\section{WORKING WITH WHOEVER IS IN GOVERNMENT}

As Professor Steele notes, there are many other challenges facing salaried services as reform moves forward. The report makes clear that the envisaged arrangements will respect salaried services' unique role in the provision of special care and caring for vulnerable patients. Signposting into dental care for such patients is particularly important and there is a clear role for carers and other health professionals outside dentistry. Signposting is also important within dentistry, so it's good to see the report recognise the importance of care pathways in ensuring that special care services are used appropriately. These should include much more opportunity than hitherto for shared care arrangements whereby patients retain a continuing care relationship with their GDP while moving into and out of salaried services for specific care when required. All too often at present patients are either discharged with no continuing care arrangement in place or kept in salaried services longer than needed.

Researching and writing a report is, however, just the beginning of a process. Given a number of well-researched and written reports over the last 20 years whose findings have not been implemented, it is easy to be cynical about the chances for this one. There does appear to be a willingness to make changes for the better though, something emphasised by the Secretary of State for Health Andy Burnham who, in accepting the report in principle, acknowledged the need to work with the BDA.

We will be studying the report carefully. Committee members are already involved in the Departmental Groups looking at Quality, Effectiveness and Outcomes and will press strongly for possible contractual changes to be piloted rigorously and evaluated before implementation.

All of this will take time. It cannot, and must not, be rushed. The public want and expect a quality NHS dental service. Dentists would like to see this too. Given the proximity of a General Election, the process of reform will be nowhere near complete by the time it takes place. Sensibly, Professor Steele has written his report in such a way as to facilitate working with whoever is in government. The journey of reform is all the more challenging because we undertake it in a difficult economic climate. Achieving and financing change, whilst properly rewarding ethical practice, will not be simple.

We must also be mindful that there are many thousands of colleagues who are struggling to deliver an excellent service within the current arrangements. Their need for support and flexibility from PCTs is still high on our agenda, particularly the issue of UDAs as a sole indicator of activity. It would be a tragedy if these colleagues are allowed to fall just when there is a real opportunity to seek long- term improvements in the NHS that benefit dentists and patients alike.

With reform come both opportunities and challenges and it is up to all of us to meet both with the same vigour, commitment and professionalism with which we undertake our clinical activities. The BDA's autonomous committees will be working hard on your behalf as the next stage of the reform process begins.

DOI: $10.1038 /$ sj.bdj.2009.572 